\title{
DIFERENÇA ENTRE DANO NÃO PATRIMONIAL INDIVIDUAL E DANO NÃO PARIMONIAL COLETIVO EM PORTUGAL
}

\section{DIFFERENCE BETWEEN INDIVIDUAL NON-HERITAGE DAMAGE AND COLLECTIVE NON-PARIMONIAL DAMAGE IN PORTUGAL}

\author{
João Paulo Antunes Machado \\ Enoque Ribeiro
}

Recebido: 01/05/2020 - Aceito: 20/05/2020

\section{RESUMO}

O presente trabalho versa sobre a diferença entre 0 dano não patrimonial individual e dano não patrimonial coletivo em Portugal, tema que anda em voga principalmente devido ao fato de, nos últimos anos, diversos ordenamentos jurídicos terem dado especial atenção para as acções colectivas. Preliminarmente, faremos, uma breve narrativa acerca da evolução histórica do direito da personalidade. Posteriormente, adentraremos no tema objeto deste estudo, cujo capítulo abrangerá as considerações iniciais acerca do assunto e, logo em seguida, tratará dos conceitos, especificidades, entendimentos e controvérsias de cada instituto. Por fim, apresentaremos as conclusões extraídas da pesquisa realizada e do confronto de idéias estabelecido diante tão importante debate.

Palavra Chave: Dano, Patrimônio, Ação Coletiva.

\section{ABSTRACT}

This paper deals with the difference between individual non-equity damage and collective non-equity damage in Portugal, theme and action mainly due to the fact that, in recent years, several legal systems that have received special attention for collective actions. Preliminarily, we will make a brief narrative about the historical evolution of personality law. Subsequently, we will enter into the subject matter of this study, the chapter will cover as recent considerations on the subject and, logo, will deal with concepts, specificities, undertakings and controversies of 
each institute. Finally, we present the conclusions drawn from the research carried out and the confrontation of ideas established such an important debate. Keyword: Damage, Patrimony, Collective Action.

\title{
1 INTRODUÇÃO
}

\subsection{NOÇÕES HISTÓRICAS}

O direito a indenização decorrente de um dano não patrimonial é uma sanção devida em razão do desrespeito a um dos direitos da personalidade. Segundo Paulo Lôbo, (2003) "A interação entre danos morais e direitos da personalidade é tão estreita que se deve indagar da possibilidade da existência daqueles fora do âmbito destes". ${ }^{1}$

No decorrer da história, notamos que a evolução do reconhecimento e da proteção dos Direitos da Personalidade caminhou, lado a lado, com o desenvolvimento da própria sociedade.

A palavra "personalidade" se origina do latim persona, que era o nome dado às máscaras utilizadas pelos atores em peças teatrais.

Os Direitos da Personalidade eram conhecidos desde a Grécia Antiga (séculos III e IV a.C.). Com a evolução das cidades, os filósofos gregos tentavam, racionalmente, explicar as mais diversas questões e fenômenos, e dentre eles, a proteção da personalidade humana, deixando assim, de lado, o pensamento mítico. Vejamos:

\begin{abstract}
A concepção de um direito geral de personalidade tomou forças no século III e IV a.C., que representou o ápice da filosofia. Nesta época, o filósofo Sócrates começa a pensar no homem como centro do universo, numa concepção cientifica ligado ao bem moral do homem, seguidos por seu aprendiz Platão e o aprendiz deste, Aristóteles.

A proteção da personalidade humana Era edificada em três pontos centrais. $O$ primeiro elaborava a noção de desprezo à injustiça, já o segundo, proibia toda e qualquer prática de atos excessivos de uma pessoa contra outra e a terceiro e por fim, a terceira, vedava a prática de atos de abuso indecoroso contra pessoa humana.
\end{abstract}

\footnotetext{
${ }^{1}$ LÔBO, Paulo. Danos morais e direitos da personalidade. Revista Jus Navigandi, ISSN 1518-4862, Teresina, ano 8, n. 119, 31 out. 2003. Disponível em: <https://jus.com.br/artigos/4445>. Acesso em: 30 jun. 2018.
} 
A proteção da personalidade humana foi criando força aos poucos por meio da tutela de violação contra a pessoa por meio da prática de ato ilícito, como os de lesão corporal, difamação e estupro. Nesta época, a tutela da personalidade humana possuía natureza exclusivamente penal.

Por preponderância da obra de Aristóteles que passou a existir a igualdade entre as pessoas e a consciência de que a Lei quem tem o dever de manter a regular relação humana na sociedade (sempre em busca do bem comum). Com base neste pensamento, inspirada pelos filósofos gregos, legitima a existência de um único e geral direito de personalidade em cada ser humano, estabelecendo uma clausula geral protetora da personalidade de cada indivíduo representada pela hybris, o qual era uma ação judicial punitiva, possuindo um caráter penal do qual punia ultrajes ou sevicias sobre o indivíduo, como nos ensina Capelo de Souza. $^{2}$

Nessa época, discutia-se sobre os direitos da personalidade, mas não havia ainda normas que efetivamente protegessem, de maneira específica, tais direitos.

O principal instrumento para proteção dos direitos da personalidade no Império Romano era a actio injuriarum, que consistia num interdito criado para defesa contra ofensas por injúria, honra, liberdade, etc.

Além dele, cumpre ressaltarmos igualmente:

(...) a Lex Cornelia (81 a.C.) que declarou ser inviolável o domicílio; a Lex Aquilia que deu direito de ação à tutela da integridade física e doisinterditos (interdictum de homine libero exhibendo e interdictum de libeirs exhibendis), ambos destinados a amparar a liberdade de alguém que estivesse injustamente retido. O primeiro, de natureza exibitória, destinava-se a amparar a liberdade, evitando-se que aspessoas livres fossem retidas por qualquer motivo. $O$ segundo, que competia a qualquer um, destinava-se restabelecer a liberdade de quem estivesse preso. ${ }^{3}$

Com a queda do Império Romano do Ocidente em 476 d.C., o Direito Romano foi substituído pelo Direito Germânico, que não possuía normas escritas (costumeiro) e não contemplava o Direito de Personalidade, pois chegava, em alguns momentos, a exaltar a vingança privada.

\footnotetext{
${ }^{2}$ SILVA, Hugo Gregório Mussi. A origem e a evolução do direitos da personalidade e a sua tutela no ordenamento jurídico brasileiro[Em linha], p. 6 e 7. [Consult. 27/10/2017]. Disponível em: http://docplayer.com.br/49390739-A-origem-e-a-evolucao-dos-direitos-da-personalidade-e-a-sua-tutelano-ordenamento-juridico-brasileiro.html

${ }^{3}$ DUTRA, Leonardo Leandro e Silva; LOPES, Gleice Finamori - Evolução histórico-conceitual dos Direitos da Personalidade [Em linha] p.7, [Consult. 27/10/2017]. Disponível em http://www.buscalegis.ufsc.br/revistas/files/anexos/15920-15921-1-PB.pdf
} 
No Século XI, surge, na Itália, a Escola de Glosadores de Bolonha, que fez com que o Direito Romano ganhasse força e voltasse a ser utilizado na Europa até o Século XIX.

Conforme demostra Hugo Gregório Mussi Silva, no final do século XIV e início do século XV, o rei D. João I implantou em Portugal o Corpus luris Civilis, as Glosas de Acúrsio e as de Bartolo4. Tais institutos não modificaram, de maneira essencial, a tutela do Direito Geral de Personalidade, permanecendo sua proteção nos mesmos termos da actio injuriarum.

Carlos Alberto Bittar leciona acerca da teoria dos direitos da personalidade e dos fatores que foram determinantes para sua formação:

A construção da teoria dos Direitos da Personalidade humana deve-se, principalmente: a) ao cristianismo, em que se assentou a idéia da dignidade do homem; b) à Escola de Direito Natural, que firmou a noção de direitos naturais ou inatos ao homem, correspondentes à natureza humana, a ela unidos indissoluvelmente e preexistente ao reconhecimento do Estado; e, c) aos filósofos e pensadores do iluminismo, em que se passou a valorizar o ser, o indivíduo frente ao Estado. ${ }^{5}$

Ocorre que, apenas no século XVII, com o Liberarismo na Inglaterra e o lluminismo na França, o Estado passou a reconhecer a proteção da pessoa humana ${ }^{6}$.

Após os horrores da Segunda Guerra Mundial, percebeu-se a necessidade de uma maior proteção aos Direitos do Homem. Sendo assim, em 10 de Dezembro de 1948, foi proclamada a Declaração Universal dos Direitos do Homem ${ }^{7}$, elevando tais Direitos a um patamar de nunca antes experimentado.

\footnotetext{
${ }^{4}$ SILVA, Hugo Gregório Mussi. A origem e a evolução dos direitos da personalidade e a sua tutela no ordenamento jurídico brasileiro [Em linha], p. 10. [Consult. 27/10/2017]. Disponível em: http://docplayer.com.br/49390739-A-origem-e-a-evolucao-dos-direitos-da-personalidade-e-a-sua-tutelano-ordenamento-juridico-brasileiro.html

${ }_{5}^{5}$ BITTAR, Carlos Alberto. Os Direitos da Personalidade. $5^{\text {a }}$. ed. Atualizada por Eduardo Cardoso Bianca Bittar. Rio de Janeiro: Forense, 2001.p. 19; apud GODOY Kêmella Gnocchi de - A evolução histórica do direito da personalidade e seu atual aspecto constitucional [Em linha]. p.04. [Consult. 27/10/2017]. Disponível em http://intertemas.unitoledo.br/revista/index.php/ETIC/article/viewArticle/1222

${ }^{6}$ GODOY, Cláudio Luiz Bueno de. A liberdade de imprensa e e os direitos da personalidade. São Paulo: Atlas, 2001. p. 19; apud GODOY Kêmella Gnocchi de - A evolução histórica do direito da personalidade e seu atual aspecto constitucional [Em linha]. p.04. [Consult. 27/10/2017]. Disponível em http://intertemas.unitoledo.br/revista/index.php/ETIC/article/viewArticle/1222

${ }^{7}$ Preâmbulo
} 
Tal declaração fez surgir o Direito da Personalidade, além de proclamar Direitos Universais mínimos inerentes a todo homem.

\author{
Após tal feito, o mundo jurídico começa a criar mecanismos que \\ possam dar efetividade aos direitos da personalidade, e o que se vê é que tais \\ direitos, juntamente com as indenizações por danos não patrimoniais (que \\ representam a sanção decorrente do desrespeito a este direito) começam a ser \\ previstas em diversas cartas constitucionais, a exemplo dos artigos 29, ํ․ 6, \\ $37^{\circ}, n^{\circ} .4$ e $60^{\circ}, n^{\circ} .1$ da CRP. ${ }^{8}$ \\ Para Paulo Lôbo (2003)
}

A inserção constitucional dos direitos da personalidade e dos danos morais consagra a evolução pela qual, ambos os institutos jurídicos têm passado. Os direitos da personalidade, por serem não patrimoniais, encontram excelente campo de aplicação nos danos morais, que têm a mesma natureza não patrimonial. Ambos têm por objeto bens integrantes da interioridade da pessoa, que não dependem da relação com os essenciais à realização da pessoa, ou seja, aquilo que é inato à pessoa e deve ser tutelado.

Os direitos da personalidade, nas vicissitudes por que passaram, sempre esbarraram na dificuldade de se encontrar um mecanismo viável de tutela jurídica, quando da ocorrência da lesão. Ante os

Considerando que o reconhecimento da dignidade inerente a todos os membros da família humana e seus direitos iguais e inalienáveis é o fundamento da liberdade, da justiça e da paz no mundo,

Considerando que o desprezo e o desrespeito pelos direitos do homem resultaram em atos bárbaros que ultrajaram a consciência da Humanidade, e que o advento de um mundo em que os homens gozem de liberdade de palavra, de crença e da liberdade de viverem a salvo do temor e da necessidade,

Considerando ser essencial que os direitos do homem sejam protegidos pelo império da lei, para que o homem não seja compelido, como último recurso, à rebelião contra a tirania e a opressão,

Considerando ser essencial promover o desenvolvimento de relações amistosas entre as nações,

Considerando que os povos das Nações Unidas reafirmaram, na Carta, sua fé nos direitos do homem e da mulher, e que decidiram promover o progresso social e melhores condições de vida em uma liberdade mais ampla, Considerando que os Estados Membros se comprometeram a promover, em cooperação com as Nações Unidas, o respeito universal aos direitos e liberdades fundamentais do homem e a observância desses direitos e liberdades,

Considerando que uma compreensão comum desses direitos e liberdades é da mais alta importância para o pleno cumprimento desse compromisso,

A Assembleia Geral das Nações Unidas proclama a presente Declaração Universal dos Direitos do Homem como o ideal comum a ser atingido por todos os povos e todas as nações, com o objetivo de que cada indivíduo e cada órgão da sociedade, tendo sempre em mente esta Declaração, se esforce, através do ensino e da educação, por promover o respeito a esses direitos e liberdades, e, pela adoção de medidas progressivas de caráter nacional e internacional, por assegurar o seu reconhecimento e a sua observância universais e efetivos, tanto entre os povos dos próprios Estados Membros, quanto entre os povos dos territórios sob sua jurisdição.

Artigo 1

Todos os homens nascem livres e iguais em dignidade e direitos. São dotados de razão e consciência e devem agir em relação uns aos outros com espírito de fraternidade.

${ }^{8}$ Artigo 29. ${ }^{\mathbf{0}}, \mathbf{n}^{\mathbf{0}}$. 6. " Os cidadãos injustamente condenados têm direito, nas condições que a lei prescrever, à revisão da sentença e à indemnização pelos danos sofridos". Artigo 37., $\mathbf{n}^{\mathbf{0}}$. 4. "A todas as pessoas, singulares ou coletivas, é assegurado, em condições de igualdade e eficácia, o direito de resposta e de retificação, bem como o direito a indemnização pelos danos sofridos". Artigo 60., $\mathbf{n}^{\mathbf{0}}$. 1. "Os consumidores têm direito à qualidade dos bens e serviços consumidos, à formação e à informação, à proteção da saúde, da segurança e dos seus interesses económicos, bem como à reparação de danos”. 
fundamentos patrimonialistas que determinaram a concepção do direito subjetivo, nos dois últimos séculos, os direitos de personalidade restaram alheios à dogmática civilística. A recepção dos danos morais foi o elo que faltava, pois constituem a sanção adequada ao descumprimento do dever absoluto de abstenção. ${ }^{9}$

\title{
2. DANO NÃO PATRIMONIAL INDIVIDUAL E DANO NÃO PATRIMONIAL COLECTIVO EM PORTUGAL.
}

Não obstante haver previsão expressa na CRP, no CC e na Lei do Consumidor, o legislador português não definiu o conceito de dano não patrimonial.

Por conta dessa falta de conceituação legal, nos socorremos de Acórdão do Tribunal da Relação de Coimbra, datado de 16/09/2014.

\begin{abstract}
A lei não define $o$ dano não patrimonial. Doutrinariamente 0 conceito é recortado pela negativa. $O$ dano diz-se não patrimonial quando a situação vantajosa lesada tenha natureza espiritual; o dano não patrimonial é o dano insusceptível de avaliação pecuniária, reportado a valores de ordem espiritual, ideal ou moral; é o prejuízo que não atinge em si o património, não o fazendo diminuir nem frustrando o seu acréscimo.

Diferentemente do que acontece com a indemnização do dano patrimonial, a do dano não patrimonial não é uma verdadeira indemnização, pois não coloca o lesado na situação em que estaria se o facto danoso não tivesse tido lugar, mediante a concessão de bens com valor equivalente ao dos ofendidos em consequência do facto. ${ }^{10}$
\end{abstract}

O dano não Patrimonial ocorre quando há uma violação a algum direito inerente à personalidade, tais como a honra, a imagem, a intimidade, a liberdade, o nome, a integridade física e psíquica, ofendendo desse modo o equilíbrio ou o bem-estar psíquico do ofendido, podendo essa violação dar-se apenas contra um indivíduo (dano não patrimonial individual) ou ser uma lesão a direitos individuais homogêneos, interesses difusos e coletivos (dano não patrimonial coletivo).

\footnotetext{
${ }^{9}$ LÔBO, Paulo. Danos morais e direitos da personalidade. Revista Jus Navigandi, ISSN 1518-4862, Teresina, ano 8, n. 119, 31 out. 2003. Disponível em: 〈https://jus.com.br/artigos/4445>. Acesso em: 30 jun. 2018.

${ }^{10}$ Acórdão do Tribunal da Relação de Coimbra. Processo nº. 597/11.0TBTNV.C1. Relator: Henrique Antunes. Datado de 16/09/2014. [Em linha].[Consult. em 27/06/2018]. Disponível em: http://www.dgsi.pt/jtrc.nsf/c3fb530030ea1c61802568d9005cd5bb/c5914b1ca2252b4d80257d5b003907cc ?OpenDocument.
} 
Como exemplo de concessão de indenização por dano não patrimonial individual, temos o Acórdão do Tribunal da Relação de Évora:

I - Tendo o trabalhador sido reintegrado na empresa em consequência do despedimento que foi declarado ilícito, não tem direito à retribuição prevista no artigo $134 .$. do Código do Trabalho por formação profissional em falta, uma vez que mantendo-se o contrato de trabalho essa formação deve ser assegurada ao trabalhador nos termos previstos no artigo 132. do Código do Trabalho;

II - Justifica-se a fixacão de uma indemnizacão por danos não patrimoniais ao trabalhador que em consequência do despedimento (ilícito) passou a andar triste e anqustiado, pois tinha a expetativa de continuar na empresa, onde já se encontrava há cerca de 5 anos. ${ }^{11}$

O dano não patrimonial colectivo está previsto no artigo $52^{\circ}, \mathrm{n} .^{\circ} 3$, da CRP, vejamos:

\begin{abstract}
"É conferido a todos, pessoalmente ou através de associações de defesa dos interesses em causa, o direito de acção popular nos casos e termos previstos na lei, incluindo o direito de requerer para o lesado ou lesados a correspondente indemnização. a) Promover a prevenção, a cessação ou a perseguição judicial das infracções contra a saúde pública, os direitos dos consumidores, a qualidade de vida e a preservação do ambiente e do património cultural"; $;^{12}$
\end{abstract}

Quando o dano ultrapassar a esfera de direitos individuais, atingindo a uma coletividade ou um grupo, temos o dano não patrimonial colectivo, instituto que vem sendo reconhecido cada vez mais, seja no âmbito do direito do consumo, no direito ambiental, quando o meio ambiente é agredido, causando danos a um número indeterminado de pessoas ou no direito do trabalho.

O instrumento processual adequado para defesa dos bens colectivos é a acção popular, que se encontra prevista na lei 83/9513.

\footnotetext{
${ }^{11}$ Acórdão do Tribunal da Relação de Évora. Processo no. 947/16.2T8EVR.E1. Relator: JOÃO NUNES. Datado de 13/07/2017. [Em linha].[Consult. em 30/06/2018]. Disponível em: http://www.dgsi.pt/jtre.nsf/134973db04f39bf2802579bf005f080b/1b6ff6ed8450042c80258192002ee9 e5?OpenDocument.

${ }^{12}$ CONSTITUIÇÃO da República. Diário da República I Série, no ${ }^{\circ} .86$ (10-04-1976) p. 738 - 775.

${ }^{13}$ LEI n. ${ }^{8} 83 / 1995$. Diário da República Série I-A, n. 201 (31-08-1995), p.5464-5467.
} 
A citada lei, no seu artigo 1ํㅡ, trás as hipóteses de cabimento da acção popular. ${ }^{14} \mathrm{E}$ nos primeiros anos de vigência da Lei, discutia-se acerca da sua abrangência, as grandes empresas argumentavam que da análise do artigo 1 da Lei n. 83/95 e no que concerne ao objecto da acção popular prevista no artigo 52 n. 3 da Constituição da República Portuguesa, estariam protegidos apenas os interesses difusos e não os interesses individuais ou colectivos.

Diante dessa situação o Supremo Tribunal de Justiça foi instado a manifestar-se e proferia sentença em 1997, no seguinte sentido:

\begin{abstract}
I - 0 artigo 1 da Lei 83/95, de 31 de Agosto, abrange não só os "interesses difusos" (interesses de toda a comunidade) como ainda os "interesses individuais homogéneos" (os que se polarizam em aglomerados identificados de titulares paralelamente justapostos).

II - O direito de reparação de danos dos assinantes do serviço telefónico por incumprimento de contrato inclui-se na categoria dos "interesses homogéneos individuais".

III - A ACOP (Associação de Consumidores de Portugal) tem legitimidade para propor acção popular que tenha por objecto 0 pedido de indemnização dos assinantes de contrato de serviço telefónico público por violação contratual da prestadora do serviço ${ }^{15}$.
\end{abstract}

Interessante perceber que o STJ deu uma interpretação não literal, não se atendo ao texto frio da Lei, o referido Tribunal teve a sensibilidade de fazer uma interpretação sistêmica, contribuindo assim para a unidade do sistema jurídico.

Dessa forma restou claro que a Lei n. 83/95, de 31 de Agosto trata dos interesses difusos e colectivos e também dos individuais homogêneos, permitindo que as associações e fundações defensoras de tais interesses sejam titulares de legitimidade activa para propor acção popular, uma vez que a defesa

\footnotetext{
${ }^{14}$ Artigo $1^{\circ}$ "1 - A presente lei define os casos e termos em que são conferidos e podem ser exercidos o direito de participação popular em procedimentos administrativos e o direito de acção popular para a prevenção, a cessação ou a perseguição judicial das infracções previstas no n. 3 do artigo $52 .^{\circ}$ da Constituição.

2 - Sem prejuízo do disposto no número anterior, são designadamente interesses protegidos pela presente lei a saúde pública, o ambiente, a qualidade de vida, a protecção do consumo de bens e serviços, o património cultural e o domínio público". ${ }^{14}$ LEI n. ${ }^{\circ} 83 / 1995$. Diário da República Série I-A, n. 201 (3108-1995), p.5464-5467.

15 Acórdão do Supremo Tribunal de Justiça. Processo nº. 97B503/JSTJ00032245. Relator: Miranda Gusmão. Datado de 23/09/19977. [Em linha].[Consult. em 30/06/2018]. Disponível em: http://www.dgsi.pt/jstj.nsf/-/5C4988169839A2ED802568FC003B7C49
} 
do interesse em causa na acção esteja expressamente incluída dentre as atribuições ou estatutos das associações ou fundações ${ }^{16}$.

Direitos difusos são metaindividuais e caracterizam-se principalmente por sua indivisibilidade, são direitos comuns a uma coletividade não determinada, que estão unidas apenas por uma situação de fato.

Direitos coletivos constituem direitos transindividuais de pessoas ligadas por uma relação jurídica base entre si ou com a parte contrária, sendo seus sujeitos indeterminados, porém determináveis. Há também a indivisibilidade do direito, pois não é possível conceber tratamento diferenciado aos diversos interessados coletivamente, desde que ligados pela mesma relação jurídica. Como exemplo, citem-se os direitos de determinadas categorias sindicais que podem, inclusive, agir por meio de seus sindicatos.

Direitos individuais homogêneos são aqueles indeterminados, que poderão ser determinadas no futuro. E cujos direitos são ligados por um evento de origem comum. Tais direitos podem ser tutelados coletivamente muito mais por uma opção de política do que pela natureza de seus direitos, que são individuais, unidos os seus sujeitos pela homogeneidade de tais direitos num dado caso. A defesa desses direito teve início nos Estados Unidos em 1966, através das chamadas "Class actions". Ex. Recall de veículos ${ }^{17}$.

\section{CONCLUSÃO}

Diante do nosso estudo, podemos compreender algumas diferenças entre o dano não patrimonial individual e dano não patrimonial colectivo em Portugal, foi possível observar também uma tendência, a de que cada vez menos o sistema preocupa-se em identificar um culpado de causar determinado prejuízo e cada vez mais em comprovar a existência de uma ofensa a um bem

\footnotetext{
${ }^{16}$ Além das associações e fundações, são legitimados a propor acção popular: 1) qualquer cidadão no gozo dos seus direitos civis e políticos, independentemente de terem ou não interesse na demanda; 2) as autarquias locais em relação aos interesses de que sejam titulares residentes na área da respetiva circunscrição e 3) o Ministério Público, na qualidade de defensor dos interesses difusos ou colectivos.

17 "Os interesses individuais homogéneos" que representa todos aqueles casos em que os membros da classe são titulares de direitos diversos, mas dependentes de uma única questão de facto ou de direito, pedindo-se para todos eles um provimento jurisdicional de conteúdo idêntico - GRINOVER, Ada Pellegrini - Revista Portuguesa de Direito de Consumo, n. 5, Janeiro, 1996, página 10.
} 
juridicamente protegido e a identificação de um responsável, que ira ressarcir a vítima.

As acções colectivas visam facilitar o acesso do cidadão comum ao judiciário, na medida em que não terá que arcar com os custos de uma demanda judicial que pode durar anos e também amplia a possibilidade do trabalhador ter seus direitos reconhecidos sem precisar se indispor pessoalmente com a empresa.

\section{REFERÊNCIAS}

Acórdão do Supremo Tribunal de Justiça. Processo nº. 97B503/JSTJ00032245. Relator: Miranda Gusmão. Datado de 23/09/19977. [Em linha].[Consult. em 30/06/2018]. Disponível em: http://www.dgsi.pt/jstj.nsf/15C4988169839A2ED802568FC003B7C49

Acórdão do Tribunal da Relação de Coimbra. Processo n‥ 597/11.0TBTNV.C1. Relator: Henrique Antunes. Datado de 16/09/2014. [Em linha].[Consult. em 27/06/2018]. Disponível em:

http://www.dgsi.pt/jtrc.nsf/c3fb530030ea1c61802568d9005cd5bb/c5914b1ca22 52b4d80257d5b003907cc?OpenDocument.

Acórdão do Tribunal da Relação de Évora. Processo no. 947/16.2T8EVR.E1. Relator: JOÃO NUNES. Datado de 13/07/2017. [Em linha].[Consult. em 30/06/2018]. Disponível em:

http://www.dgsi.pt/jtre.nsf/134973db04f39bf2802579bf005f080b/1b6ff6ed84500 42c80258192002ee9e5?OpenDocument

CONSTITUIÇÃO da República. Diário da República I Série, no. 86 (10-041976) p. $738-775$.

DECLARAÇÃO Universal dos Direitos Humanos. [Em linha] Consult.

27/06/2018. Disponível em: https://dre.pt/declaracao-universal-dos-direitoshumanos

BITTAR, Carlos Alberto. Os Direitos da Personalidade. $5^{\mathrm{a}}$. ed. Atualizada por Eduardo Cardoso Bianca Bittar. Rio de Janeiro: Forense, 2001.p. 19; apud GODOY Kêmella Gnocchi de - A evolução histórica do direito da personalidade e seu atual aspecto constitucional [Em linha]. p.04. [Consult. 27/10/2017]. Disponível em http://intertemas.unitoledo.br/revista/index.php/ETIC/article/viewArticle/1222

DUTRA, Leonardo Leandro e Silva; LOPES, Gleice Finamori - Evolução histórico-conceitual dos Direitos da Personalidade [Em linha] p.7, [Consult. 
27/10/2017].

Disponível

em

http://www.buscalegis.ufsc.br/revistas/files/anexos/15920-15921-1-PB.pdf

GODOY Kêmella Gnocchi de - A evolução histórica do direito da

personalidade e seu atual aspecto constitucional [Em linha]. p.04. [Consult. 27/10/2017]. Disponível em

http://intertemas.unitoledo.br/revista/index.php/ETIC/article/viewArticle/1222

LEI n. 83/1995. Diário da República Série I-A, n.ำ201(31-08-1995), p. 54645467.

LÔBO, Paulo. Danos morais e direitos da personalidade. Revista Jus

Navigandi, ISSN 1518-4862, Teresina, ano 8, n. 119, 31 out. 2003. Disponível em: <https://jus.com.br/artigos/4445>. Acesso em: 30 jun. 2018.

SILVA, Hugo Gregório Mussi. A origem e a evolução dos direitos da personalidade e a sua tutela no ordenamento jurídico brasileiro [Em linha], p. 10. [Consult. 27/10/2017]. Disponível em: http://docplayer.com.br/49390739A-origem-e-a-evolucao-dos-direitos-da-personalidade-e-a-sua-tutela-noordenamento-juridico-brasileiro.html 